\title{
Sobre o Custo do Tempo para a Competitividade da Indústria Brasileira: Diagnóstico e síntese dos impactos econômicos da facilitação do comércio no Brasil
}

\author{
Lucas P. do C. Ferraz ${ }^{1}$
}

Raoni Marinho ${ }^{2}$

\section{Resumo}

Este artigo analisa a importância dos atrasos portuários para a competitividade da indústria de transformação no Brasil. Com base em estimativas recentes sobre o custo diário dos atrasos comerciais e em bases de dados do Banco Mundial e do GTAP (Global Trade Analysis Project), revela a magnitude destas barreiras sob a forma de seus equivalentes ad valorem. Em seguida, por meio de simulações em equilíbrio geral, estima o impacto da melhoria dos processos aduaneiros sobre o desempenho da indústria de transformação no Brasil, sob diferentes cenários. Os resultados obtidos ressaltam o caráter estratégico da facilitação do comércio para a economia Brasileira, em particular sua indústria de transformação e sua inclusão como item relevante para a agenda de crescimento de longo prazo do país.

\section{Palavras-Chave}

Facilitação de comércio. Indústria. Equilíbrio Geral.

\begin{abstract}
This article evaluates the importance of delays at customs for the competitiveness of the transformation industry in Brazil. Based on recent estimations of one-day costs of delays for trade as well as in databases of the World Bank and GTAP (Global Trade Analysis Project) it reveals the magnitude of the time barriers under its ad valorem equivalent form. Next, through general equilibrium simulations, this paper estimates the impacts of streamlining customs procedures over the performance of the transformation industry in Brazil, under different scenarios. Simulation results highlight the strategic character of trade facilitation reforms for the Brazilian economy, particularly for its transformation industry, and the priority of its inclusion as a relevant topic in the long-term growth national agenda.

1 Professor - Escola de Economia de São Paulo da Fundação Getúlio Vargas (EESP/FGV)

Endereço: Rua Itapeva, 474 - São Paulo/SP - Brasil - CEP: 01332-000 - E-mail: lucas.ferraz@fgv.br http://orcid.org/0000-0001-7341-283X

2 Mestre em Economia - Escola de Economia de São Paulo da Fundação Getúlio Vargas (EESP/FGV) Endereço: Rua Itapeva, 474 - São Paulo/SP - Brasil - CEP: 01332-000

E-mail: raonirmarinho@gmail.com - https://orcid.org/0000-0002-3303-4165

Recebido: 01/04/2016. Aceite: 06/06/2018.
\end{abstract}

(c) (i) (\$) Esta obra está licenciada com uma Licença Creative Commons Atribuição-Não Comercial 4.0 Internacional. 


\section{Keywords}

Trade facilitation. Industry. General Equilibrium.

\section{JEL Classification}

L91. L98. C68. F13.

\section{Introdução}

O Acordo de Facilitação de Comércio de Bali, ${ }^{1}$ primeiro acordo multilateral firmado no âmbito da atual rodada Doha da OMC (Organização Mundial do Comércio), concentra-se, fundamentalmente, no aumento da eficiência dos processos aduaneiros existentes em seus países membros. Uma vez que suas diretrizes sejam seguidas, espera-se que as economias percebam aumento substancial nos fluxos de importação e exportação de mercadorias, sobretudo no caso dos países pobres ou em desenvolvimento, onde a logística portuária tende a ser menos eficiente.

Ao mesmo tempo em que o número de acordos preferenciais de comércio evolui em escala global e as tarifas efetivas de importação são significativamente reduzidas, o tema da facilitação do comércio, encenado de forma geral pelos atrasos aduaneiros, é destacado pela literatura empírica de comércio internacional como uma barreira não tarifária, cuja redução tem importância crucial para a continuidade do crescimento do comércio mundial. Mais recentemente, com o significativo aumento das exportações de bens intermediários manufaturados, o fator tempo se tornou condição necessária para a integração das economias às chamadas cadeias globais de valor.

Considerando esses aspectos, e tendo em vista as características da estrutura aduaneira brasileira, o presente artigo busca estimar os possíveis impactos das reduções dos atrasos portuários sobre a economia do país. Além disso, busca-se também entender os desdobramentos específicos para os diferentes setores produtivos da economia doméstica, em particular para a sua indústria de transformação, a qual, como será visto mais adiante, tende a ser mais sensível aos atrasos portuários vis à vis os demais setores da economia.

1 Para detalhes do acordo, ver: www.wto.org/english/tratop_e/tradfa_e/tradfa_e.htm. 
Tais objetivos serão perseguidos utilizando-se como ferramenta primária a modelagem em equilíbrio geral computável, tendo por base dados consolidados e estimativas recentes de custos diários de atrasos para uma ampla gama de mercadorias, sob duas perspectivas centrais: em primeiro lugar, da aderência unilateral do governo brasileiro aos pressupostos do Acordo de Bali, resultando em queda significativa dos atrasos portuários no Brasil e, em segundo lugar, sob a hipótese de que as demais economias do mundo também ratifiquem o acordo e procedam a uma redução proporcional dos atrasos em seus portos.

Os resultados obtidos neste estudo sugerem que os atrasos aduaneiros são hoje, para o Brasil, barreiras ao comércio mais relevantes que as próprias barreiras tarifárias existentes, tanto domesticamente, como em seus principais destinos comerciais. Além disso, sugere que os atrasos portuários são particularmente prejudiciais para a indústria de transformação, haja vista a maior sensibilidade ao tempo para os bens capital-intensivos vis-àvis os demais bens da economia. Neste sentido, aponta que a melhoria da logística de comércio no Brasil, ainda que uma política pública de cunho horizontal, é potencialmente efetiva como política industrial, capaz de aumentar a inserção da indústria brasileira no comércio internacional.

Este artigo está organizado em mais cinco seções. Na seção 2 é feita uma revisão da literatura. Na seção 3 é apresentada a base de dados utilizada. A seção 4 discute os principais aspectos e premissas da modelagem em equilíbrio geral. Na seção 5 são apresentados os resultados e algumas implicações de política pública. A seção 6 apresenta as principais conclusões do trabalho.

\section{Revisão da Literatura}

Para a estimativa dos impactos econômicos da facilitação de comércio, ${ }^{2}$ predominam na literatura empírica a utilização de modelos

2 Segundo a OCDE (Organização para a Cooperação e Desenvolvimento Econômico), o termo facilitação de comércio se refere à "políticas e medidas voltadas para redução dos custos de comercialização por meio do aumento da eficiência em cada estágio das transações internacionais". Já de acordo com a definição da OMC (Organização Mundial de Comércio), facilitação de comércio é a 'simplificação de procedimentos de troca', entendido como 'atividades, práticas e formalidades envolvidas na coleta, apresentação, comunicação e processamento de dados necessário para a movimentação de bens nas trocas internacionais' 
econométricos gravitacionais (Anderson 1979; Anderson \& Wincoop 2003; Yotov et al. 2016) e modelos de equilíbrio geral computável (Ginsburgh \& Keyzer 1997; Hertel 1997; Dixon \& Jorgenson 2013). Sobre a primeira vertente da literatura, Wilson et al. (2005) estimam o impacto da facilitação por meio de um modelo gravitacional com dados em painel, para uma amostra de 75 países. Os autores trabalham com quatro medidas de facilitação do comércio (infraestrutura portuária aérea e marítima, qualidade das aduanas, ambiente regulatório e e-business) e estimam ganhos potenciais da ordem de $\$ 377$ bilhões em exportações adicionais, quando os indicadores nacionais de facilitação são aproximados em 50\% em relação às respectivas médias mundiais. Iwanow e Kirkpatrick (2007) empregam um modelo gravitacional clássico, estendido para um grupo de indicadores relacionados à facilitação do comércio, qualidade do ambiente regulatório e da infraestrutura, a fim de estimar seus respectivos impactos sobre as transações bilaterais, utilizando uma amostra representativa de países. Os resultados estimados sugerem que uma melhora da ordem de $10 \%$ no indicador de facilitação de comércio levaria a um aumento médio das exportações em 5\%. Melhorias percentuais idênticas nos indicadores de qualidade regulatória e infraestrutura resultariam em aumentos médios dos fluxos bilaterais de comércio da ordem de $9-11 \%$ e $8 \%$, respectivamente. Os autores concluem que, embora importante sob o ponto de vista individual, o aumento da eficiência portuária deve vir acompanhado de reformas que também envolvam melhorias mais amplas nas cadeias logísticas do comércio internacional.

Empregando metodologia similar, porém com um detalhamento mais amplo, o relatório da OCDE (2013) apresenta estimativas dos impactos de vários indicadores de facilitação de comércio sobre os fluxos bilaterais, para um grupo de 106 países não membros da OCDE. No relatório são construídos dezesseis indicadores de Facilitação de Comércio ${ }^{3}$ (IFCs), cujos impactos são estimados a partir de um modelo gravitacional clássico, estendido para incluir tais indicadores e inferir suas respectivas elasticidades. Os exercícios econométricos realizados pela OCDE sugerem que as medidas de facilitação com maior impacto sobre o volume comercializado estão relacionadas à (i) disponibilidade de informação, (ii) harmonização e simplificação de documentos, (iii) automação de processos e gestão de

3 Mais especificamente, cada um dos indicadores busca mensurar os seguintes determinantes: disponibilidade de informação, envolvimento da comunidade comercial, resoluções antecipadas, procedimento de recursos, taxas, formalidades - documentação, automação e procedimentos, cooperação interna, cooperação externa, consularização, governança e imparcialidade, taxas de trânsito, formalidades de trânsito, garantias de trânsito e acordos e cooperação de trânsito. 
riscos, (iv) simplificação dos procedimentos de fronteiras e (v) boa governança e imparcialidade. Como pode ser observado, todas estas medidas estão fortemente correlacionadas com os atrasos portuários, o quais serão objeto central do presente trabalho.

Por meio de uma equação gravitacional em diferenças e dados de exportações bilaterais, em conjunto com o tempo despendido no processo de exportação da fábrica ao porto para uma amostra de 98 países, Djankov et al. (2010) sugerem que o efeito de um dia de atraso pode significar cerca de $1 \%$ a menos em exportações para um país. Em uma perspectiva equivalente, os autores sugerem que cada dia de atraso corresponde, em média, a um distanciamento adicional de $70 \mathrm{~km}$ do país exportador ao país de destino. Já Persson (2008) sugere que a redução do tempo de exportação (importação) em um dia, implicaria incremento das exportações (importações) de magnitude equivalente a 1\% (0.5\%), consistente com as estimativas de Djankov et al. (2010). Nordas e Piermartini (2004), por sua vez, ressaltam a importância do tempo para a conexão das indústrias nacionais às cadeias globais de valor, colocando a qualidade logística de um país como condição necessária para a sua integração ao comércio de bens intermediários, ainda mais importante que eventuais cortes tarifários. Sobre a variedade de bens exportados, Dennis e Shepherd (2011) sugerem que a melhoria dos indicadores de facilitação de comércio atua no sentido de ampliar a diversificação da pauta exportadora de um país, contribuindo não somente para a expansão da margem intensiva do comércio, como também para a sua margem extensiva.

Quanto a abordagem via modelos de equilíbrio geral computável, estudo realizado pela APEC (1999), utilizando a versão dinâmica do modelo GTAP - Global Trade Analysis Project (Ianchovichina \& Walmsley 2012), aponta que uma redução de $1 \%$ nos custos alfandegários (diretos e indiretos) ${ }^{4}$ para países industrializados, e de $2 \%$ para países em desenvolvimento, implicaria um ganho anual de PIB de até 0,25 p.p para a região da APEC (Asia-Pacific Economic Cooperation). O trabalho de Dee (1998) utiliza um modelo EGC dinâmico, em competição imperfeita, também para o caso dos países da APEC. O autor estima que uma redução uniforme de 5\% nos custos alfandegários (diretos e indiretos) é capaz de gerar incrementos de renda da ordem de $1,1 \%$ de PIB para os países do bloco.

${ }^{4}$ Custos diretos envolvem desembolsos efetivos (ex. taxas portuárias), enquanto os custos indiretos se referem aos atrasos aduaneiros. Este trabalho estará focado, pois, nos custos indiretos relacionados à facilitação do comércio. 
Para estimar os impactos da facilitação do comércio em nível global, Francois et al. (2003) utiliza uma versão estendida do modelo GTAP estático (Hertel 1997), incorporando uma estrutura de mercado em competição monopolística no setor de bens manufaturados. Assumindo uma redução de $1,5 \%$ e de 3\% nos custos alfandegários totais (diretos e indiretos), os autores estimam um incremento nas taxas de crescimento anuais do PIB global da ordem de $0,25 \%$ e $0,52 \%$, respectivamente. Já o relatório da OECD (2003), utilizando a estrutura básica do modelo GTAP (estática e com competição perfeita), estima que a redução de $1 \%$ nas barreiras alfandegárias traria um impacto estimado da ordem de $0,26 \%$ sobre o crescimento anual do PIB global. O trabalho de Hertel et al. (2001) estima os impactos econômicos esperados para o acordo preferencial de comércio entre Japão e Singapura, via modelagem EGC dinâmica. Considerado um acordo "New Age", a negociação previa, para além dos instrumentos tradicionais do GATT, como cotas, tarifas e subsídios, também a negociação de barreiras não tarifárias, sobretudo em facilitação de comércio, onde os autores reportam ganhos potenciais significativos. A contribuição metodológica mais importante do trabalho de Hertel et al. (2001), contudo, reside na simulação da redução dos atrasos portuários como ganhos potenciais de eficiência no comércio bilateral, os quais podem ser também entendidos como choques positivos de demanda, quando ao fator tempo é atribuído uma dimensão de qualidade capaz de influenciar o comportamento do consumidor-importador.

A maior parte das análises de impacto reportadas na literatura empírica de facilitação do comércio, realizadas por meio de modelos de equilíbrio geral computável, são baseadas, contudo, em estimativas ad hoc dos custos implícitos (indiretos) dos atrasos aduaneiros. O presente artigo é, pois, o primeiro a utilizar estimativas de custos dos atrasos portuários para o Brasil (realizadas por Hummels \& Schaur 2013) e a incorporá-las em um modelo EGC de larga escala, possibilitando a captação dos prováveis ganhos de comércio em um arcabouço de equilíbrio geral.

Alguns dos principais resultados de Hummels e Schaur são úteis para o entendimento das discussões que se seguirão ao longo deste texto. Por exemplo, os autores destacam que os custos associados aos atrasos na entrega podem ser magnificados para bens associados a cadeias globais/regionais de valor. A ideia é que o atraso na entrega de um dado bem intermediário pode afetar negativamente todos os estágios de produção envolvidos na fabricação de um bem final, causando spillovers negativos ao longo de 
toda a cadeia de valor global. Outro resultado importante, e consequência do resultado mencionado anteriormente, é a significativa heterogeneidade nas estimativas dos custos dos atrasos em função do tipo de produto em questão. No que tange ao Brasil, os resultados encontrados por Hummels e Schaur são sugestivos de que, para além dos problemas de produtividade setorial relativa, o custo dos atrasos portuários domésticos podem ter impactos não desprezíveis sobre a composição da pauta de comércio brasileira, contribuindo, por exemplo, para o declínio da participação de produtos de alto valor agregado no total exportado pelo país.

Como será mostrado nas próximas seções, atrasos portuários representam barreiras comerciais potencialmente mais relevantes que barreiras tarifárias, sendo particularmente prejudiciais para a competitividade dos bens manufaturados produzidos e exportados pela indústria Brasileira.

\section{Aspectos da Modelagem}

Esta seção apresenta a base de dados utilizada neste estudo, os tratamentos realizados para adequação ao seu escopo, a definição dos aspectos da modelagem e das premissas utilizadas.

\subsection{Base de Dados}

As simulações realizadas neste estudo utilizaram três fontes primárias de dados: (1) a matriz de insumo produto global do GTAP 8; (2) o custo diário dos atrasos, estimados para vários produtos por Hummels \& Schaur (2013); (3) a média nacional dos atrasos portuários, estimadas para vários países pelo Doing Business (Banco Mundial).

\subsubsection{A Base GTAP 8}

A base de dados global GTAP 8 combina informações de comércio bilateral, custos de transporte e proteção tarifária, caracterizando as ligações econômicas entre 129 regiões e 57 setores por região, a partir das matrizes de insumo produto nacionais fornecidas por cada país representado 
na base. Adicionalmente, a base de dados contém informações sobre as relações de insumo-produto por regiões individuais, as quais revelam as conexões intersetoriais dentro de cada região. O conjunto dos dados é harmonizado e completado com fontes adicionais de informações, descrevendo a economia mundial para o ano base 2007 (a última base de dados disponível para o GTAP até a realização deste estudo). ${ }^{5}$

\subsubsection{Cálculo do Equivalente Tarifário dos Atrasos Portuários}

Para cada uma das 129 regiões e 57 setores considerados neste estudo, têm-se, a partir das estimativas realizados por Hummels \& Schaur (2013) para cerca de 5.000 produtos ao nível de desagregação HS6, os custos dos atrasos (por dia) referenciados pelo seu equivalente ad valorem. A multiplicação destes valores pelo tempo médio para exportar e importar no Brasil, a partir dos dados do Doing Business (Tabela 1), permite a estimativa do equivalente ad valorem referente aos atrasos portuários totais no Brasil, tanto para as exportações, quanto para as importações.

O procedimento para o cálculo do equivalente tarifário dos atrasos portuários é realizado em três etapas. Na primeira etapa, descrita com detalhes em Hummels \& Schaur (2013), estima-se o custo de um dia de atraso para cerca de 5000 produtos. Para tanto, os autores utilizam uma base de dados ampla, a partir de duas fontes de informações distintas. A primeira delas reporta os produtos importados pela economia americana ao nível HS6, no período 1991-2005, com valores mensais, quantidades, modal de transporte utilizado (aéreo ou marítimo, com os valores dos respectivos fretes), desagregados por produto, porto de entrada e país exportador. A segunda fonte de dados reporta o tempo de comercialização (shipping times) entre os portos de saída (países exportadores) e os portos de entrada na economia americana. ${ }^{6} \mathrm{~A}$ ideia é explicar a escolha da via aérea em função do prêmio pago por esta via, além do tempo em dias economizado. ${ }^{7}$ Hummels \& Schaur estimam um custo implícito em cada dia adicional que

5 Uma descrição mais detalhada da base de dados GTAP 8 pode ser encontrada em : https://www.gtap.agecon.purdue.edu/databases/v8/default.asp.

6 Port2port Evaluation tool, fourth quarter 2006, Compair data, Inc.

7 No modelo econométrico de Hummels \& Schaur (2013), o tempo de translado aéreo é aproximado para 1 dia, qualquer que seja o par produto-país exportador. Portanto, por construção, os dias economizados por via aérea corresponderão aos dias necessários para o translado marítimo, subtraídos da unidade. 
uma mercadoria demora para ser entregue ao importador, na forma do seu equivalente tarifário. Para tanto, os autores partem da tomada de decisão de exportadores entre utilizar transporte marítimo ou aéreo. A metodologia consiste em explorar o trade-off dos maiores custos de frete por via aérea, contra os benefícios de se agilizar a entrega de um produto. Dito de outra forma, a proposta é extrair a disposição dos consumidores a pagar mais caro pelo tempo salvo via exportação aérea, tendo como alternativa o transporte marítimo, mais barato, porém mais lento. Segundo estimativas dos autores, cada dia em trânsito custa, em média, entre $0,6 \%$ a 2,1 \% do valor da carga comercializada. Além disso, Hummels \& Schaur apontam que a sensibilidade ao tempo do comércio para produtos manufaturados (partes e componentes, por exemplo) é cerca de 60\% maior, em média, quando comparada a outros produtos. A segunda etapa do procedimento consiste na adequação dos custos diários dos atrasos, originalmente estimados ao nível HS6, para os (macro) setores correspondentes da base GTAP 8. Esta última, como já mencionado, contém 57 setores, sendo 42 referentes a bens e 15 a serviços. Portanto, tendo por base a "quebra" setorial de cada um dos 42 setores da base GTAP 8 em seus respectivos códigos HS6, foi possível construir uma média ponderada setorial, tanto para exportação, quanto para importação, para cada um dos 129 países e cada relação bilateral de comércio existente na base GTAP 8. Por construção, o valor das médias ponderadas setoriais será função da pauta de exportação/importação ao nível HS6 de um determinado país, para o resto do mundo. Por exemplo, países que exportam majoritariamente bens manufaturados, como é o caso dos países da OCDE, tenderão a ser mais penalizados por atrasos portuários vis à vis países majoritariamente exportadores de commodities, como é o caso dos países da OPEP. Isto porque, segundo Hummels \& Schaur, o custo diário de atrasos para bens manufaturados tende a estar entre os maiores dentre todos os estimados em sua amostra, contendo cerca de 5000 produtos. $^{8}$ Por fim, a terceira etapa do procedimento consiste em estimar o equivalente tarifário "total" para cada

\footnotetext{
8 Apesar de trabalharem com dados de importação da economia americana, as estimativas de custo diário dos atrasos, realizadas por Hummels \& Schaur, não são, a priori, país-específicas. No modelo desenvolvido pelos autores, o parâmetro equivalente ao custo diário dos atrasos capta a desutilidade do importador com eventuais atrasos de entrega, representando uma dimensão da qualidade média atribuída ao produto importado, que pode ter origem em países os mais diversos. No cálculo feito pelos autores, esta dimensão de qualidade é capturada "livre" da influência da elasticidade de substituição entre os bens consumidos pelos importadores americanos, a qual é, claramente, país-específica. Portanto, como os próprios autores deixam claro nas conclusões do seu artigo (página 2958), a base de dados estimada por eles pode ser potencialmente utilizada para estudos de facilitação de comércio em outros países: "With our estimates of the value of each day saved one can then calculate the monetary benefits of these initiatives and how they compare to the cost incurred".
} 
um dos 129 países e respectivos fluxos bilaterais de comércio. Para tanto, uma vez calculadas as médias ponderadas da etapa 2, multiplicaram-se os valores médios diários pelo tempo médio dos atrasos portuários (nacionais) estimados pelo Doing Business (Trading Across Borders, Banco Mundial), conforme ilustrado na Tabela abaixo, para uma pequena amostra de países, incluindo o Brasil. ${ }^{9}$

Tabela 1 - Atrasos Portuários: Exportação/Importação (2012)

\begin{tabular}{|c|c|c|c|c|c|c|c|c|c|c|}
\hline \multirow[b]{2}{*}{ Região } & \multicolumn{5}{|c|}{ Tempo para exportação (dias) } & \multicolumn{5}{|c|}{ Tempo para importação (dias) } \\
\hline & $\begin{array}{c}\text { Preparação de } \\
\text { documentos }\end{array}$ & $\begin{array}{c}\text { Desembaraço } \\
\text { e inspeções }\end{array}$ & $\begin{array}{c}\text { Manuseio } \\
\text { portuário }\end{array}$ & $\begin{array}{c}\text { Manuseio } \\
\text { interno }\end{array}$ & Total & $\begin{array}{c}\text { Preparação de } \\
\text { documentos }\end{array}$ & $\begin{array}{c}\text { Desembaraço } \\
\text { e inspeções }\end{array}$ & $\begin{array}{c}\text { Manuseio } \\
\text { portuário }\end{array}$ & $\begin{array}{c}\text { Manuseio } \\
\text { interno }\end{array}$ & Total \\
\hline África do Sul & 8 & 2 & 4 & 2 & 16 & 7 & 2 & 9 & 3 & 21 \\
\hline Alemanha & 4 & 1 & 2 & 2 & 9 & 3 & 1 & 1 & 2 & 7 \\
\hline América Latina e Caribe & - & - & - & - & 17 & - & - & - & - & 19 \\
\hline Argentina & 6 & 2 & 2 & 2 & 12 & 22 & 3 & 3 & 2 & 30 \\
\hline ASS & - & - & - & - & 30 & - & - & - & - & 38 \\
\hline Brasil & 6 & 3 & 3 & 1 & 13 & 8 & 4 & 3 & 2 & 17 \\
\hline China & 14 & 2 & 3 & 2 & 21 & 15 & 4 & 3 & 2 & 24 \\
\hline EUA & 2 & 1 & 2 & 1 & 6 & 2 & 1 & 1 & 1 & 5 \\
\hline Europa e Ásia Central & - & - & - & - & 24 & - & - & - & - & 26 \\
\hline França & 4 & 1 & 3 & 2 & 10 & 5 & 1 & 3 & 2 & 11 \\
\hline Holanda & 4 & 1 & 1 & 1 & 7 & 3 & 1 & 1 & 1 & 6 \\
\hline Índia & 8 & 2 & 3 & 3 & 16 & 8 & 4 & 5 & 3 & 20 \\
\hline Italia & 11 & 2 & 3 & 3 & 19 & 10 & 2 & 3 & 3 & 18 \\
\hline Leste Asiático & - & - & - & - & 20 & - & - & - & - & 21 \\
\hline MENA & - & - & - & - & 19 & - & - & - & - & 24 \\
\hline Rússia & 13 & 1 & 3 & 5 & 22 & 12 & 1 & 2 & 5 & 20 \\
\hline Sul Asiático & - & - & - & - & 33 & - & - & - & - & 34 \\
\hline
\end{tabular}

Fonte: Adaptado de Doing Business (2013).

Nota: A média leva em conta os intervalos de tempo gastos para completar todos os procedimentos necessários para a exportação ou para a importação de um container de 20ft. Caso alguns desses procedimentos possam ser acelerados (ainda que implique em custos adicionais), são escolhidos os procedimentos legais mais rápidos.

A Tabela 1 reporta o tempo médio gasto nos portos, conforme categoria de procedimentos, para uma amostra de países/regiões. A obtenção de documentação vai desde a elaboração e o processamento de documentos, até a preparação para o desembaraço, o que abrange inspeções anteriores ao carregamento. Desembaraços e inspeções tratam da verificação de documentação, controles e inspeções técnicas e sanitárias. O manuseio portuário refere-se às atividades desenvolvidas dentro do porto, como a espera

9 Para detalhes sobre a metodologia para a estimativa do tempo médio dos atrasos portuários ver www.doingbusiness.org/methodologysurveys/tradingacrossborders.aspx. Trata-se de médias de atrasos nacionais, compatíveis com a estrutura de representação do modelo GTAP, a qual, em seu estado padrão, não possibilita a incorporação de heterogeneidades portuárias em nível micro-regional. Vale ressaltar que as médias nacionais reportadas para os diversos países são referendadas por especialistas locais. 
para carregar os containers nas embarcações. $\mathrm{O}$ manuseio interno envolve a obtenção e o carregamento de containers, o transporte até a fronteira, espera para carregamento, espera para cruzamento de fronteira, e transporte da fronteira até o porto (Djankov, Freund e Pham 2010).

O tempo gasto no Brasil em procedimentos anteriores ao carregamento é praticamente equivalente ao tempo total dos demais procedimentos, o que ocorre também para demais países em desenvolvimento. Os maiores intervalos de tempo totais aparecem na África Subsaariana. Também merece destaque o longo intervalo de tempo necessário para a documentação de importações na Argentina, que leva em média 22 dias.

Comparando-se com os demais países reportados no ranking do Doing Business (amostra de 189 países/regiões), o tempo médio de exportação para o Brasil toma a posição de número 64, sendo similar ao tempo encontrado para países como Arábia Saudita, República Dominicana, El Salvador, Romênia e Turquia. Para o tempo médio de importação, o Brasil fica na posição 87, em conjunto com a Arábia Saudita, além da Bulgária, Jamaica, Paquistão, Peru, e República Tcheca.

\subsection{O Custo do Tempo para as Relações Comerciais do Brasil}

As Figuras 1 e 2 ilustram o equivalente ad valorem dos atrasos aduaneiros calculados para um grupo de países, incluindo o Brasil, a partir das bases de dados utilizadas e discutidas no item 3.1. O resultado encontrado é tanto função do tempo médio de atraso nos portos, assim como da composição setorial da pauta de exportação/importação de um dado país. Desta forma, tudo o mais constante, quanto maior o tempo médio de atraso em portos, maior será o equivalente ad valorem de um dado país, tanto para suas exportações quanto para suas importações. No que tange à composição setorial da pauta comercial, tudo o mais constante, quanto maior a participação de produtos manufaturados nas suas exportações e importações, maior será o equivalente ad valorem e, portanto, a relevância dos atrasos portuários para o seu desempenho comercial.

Índia, China e África do Sul). Ainda que o tempo médio para exportar na Alemanha (9 dias) seja mais baixo que no Brasil (13 dias), o maior equivalente ad valorem obtido para o primeiro é função da composição de sua 
pauta de exportação, fortemente concentrada em produtos manufaturados. Vale ressaltar a menor magnitude do custo dos atrasos portuários para os Estados Unidos, tanto para exportação, quanto para importação, consequência direta da alta eficiência média de seus portos (6 e 5 dias de atraso médio, respectivamente), em que pese a predominância de produtos capital intensivos em sua pauta de exportação.

As Figuras 3 e 4 representam o equivalente ad valorem dos atrasos portuários por parceiro comercial do Brasil, para as exportações e importações de produtos manufaturados (indústria de transformação). Enquanto a Figura 3 faz um comparativo com as tarifas médias impostas às exportações de produtos manufaturados Brasileiros por país de destino, a Figura 4 faz um comparativo com as tarifas médias de importação impostas pelo Brasil por país/região de origem.

Conforme observado, o equivalente ad valorem dos atrasos aduaneiros tende a ser maior que a tarifa de importação aplicada, tanto para as exportações bilaterais de produtos manufaturados pelo Brasil, quanto para as suas importações bilaterais. Este resultado sugere a importância do tempo para o desempenho comercial da indústria brasileira e, mais importante, que a melhoria deste desempenho pode ser alcançada, em princípio, por medidas unilaterais de caráter regulatório como, por exemplo, a redução da burocracia portuária e a melhor coordenação dos órgãos anuentes envolvidos nos procedimentos de importação e exportação no país.

As Figuras 5 e 6 reportam o equivalente ad valorem dos atrasos portuários nas exportações e importações do Brasil, respectivamente, para 42 setores da economia, compreendendo (da esquerda para a direita) 13 setores agrícolas, 6 da indústria extrativa e 23 setores da indústria de transformação. Conforme observado, tanto para as exportações, quanto para as importações, os setores que compõem a indústria de transformação, por serem capital intensivos (Hummels \& Schaur 2013), são os mais sensíveis aos atrasos portuários. Desta forma, uma vez reduzido o tempo dos atrasos nos portos do Brasil, conforme previsto no acordo de facilitação do comércio da OMC, é esperado que os setores que compõem a indústria de transformação sejam os mais atingidos por esta medida, por meio do aumento da sua inserção no comércio internacional. 


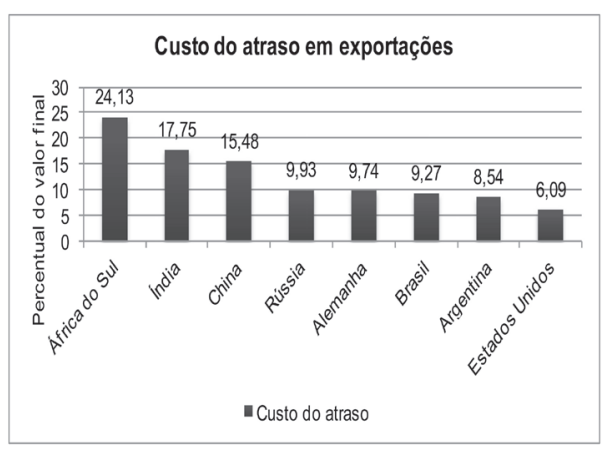

Figura 1 - Equivalente Ad Valorem dos atrasos nas exportações totais (2012). Fonte: Elaboração própria.

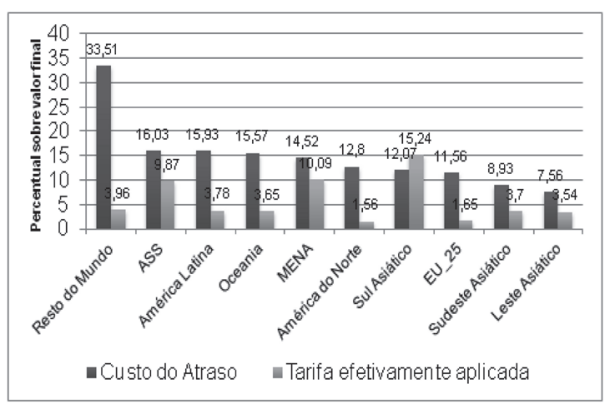

Figura 3 - Equivalente Ad Valorem dos atrasos nas exportações de manufaturados e tarifa aplicada no destino (2012).

Fonte: Elaboração própria. Nota: Mena (Oriente médio e norte da África); ASS (África subsaariana)

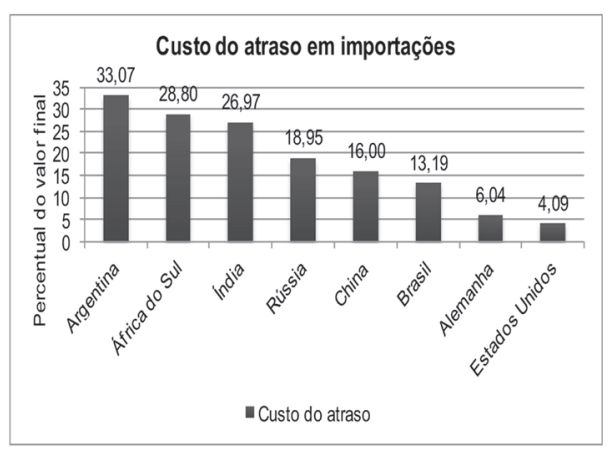

Figura 2 - Equivalente Ad Valorem dos atrasos nas importações totais (2012). Fonte: Elaboração própria.

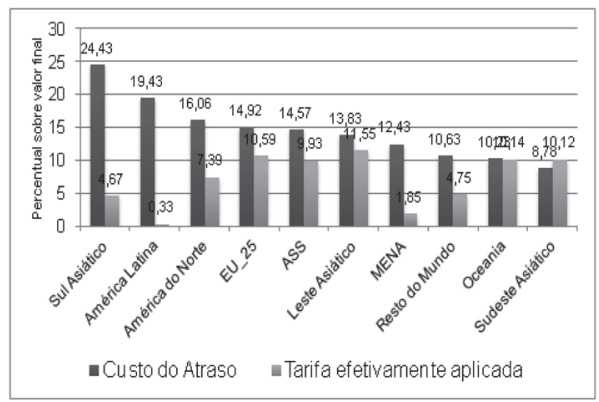

Figura 4 - Equivalente Ad Valorem dos atrasos nas importações de manufaturados e tarifa aplicada no destino (2012).

Fonte: Elaboração própria. Nota: Mena (Oriente médio e norte da África); ASS (África subsaariana) 


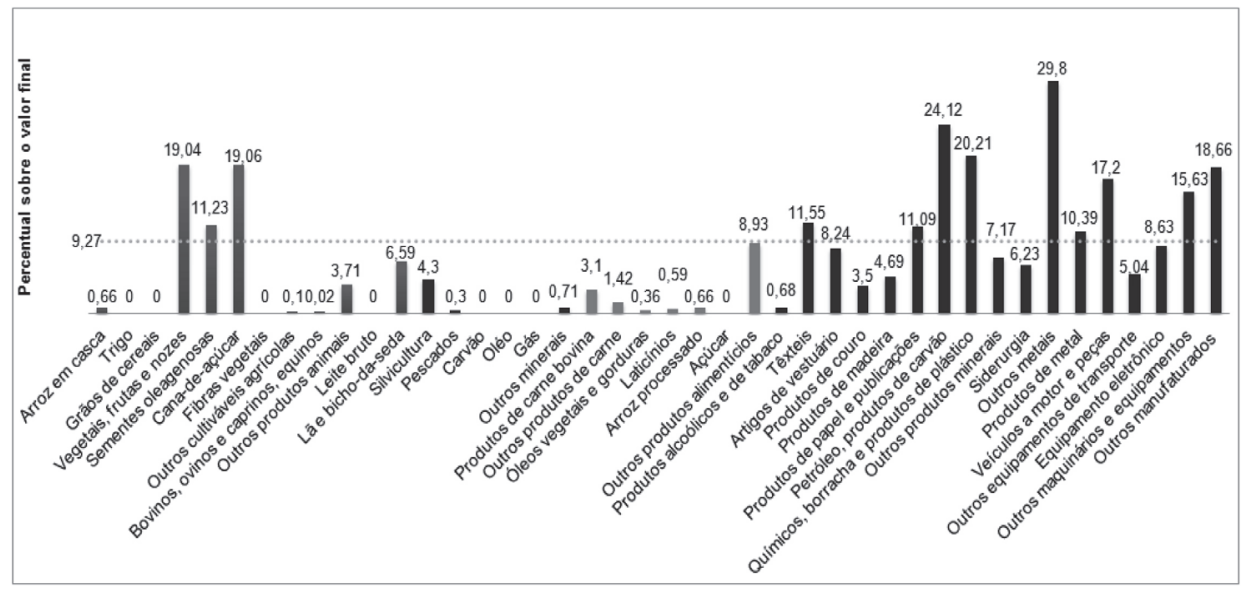

Figura 5 - Equivalente ad valorem das exportações setoriais (2012)

Fonte: elaboração própria.

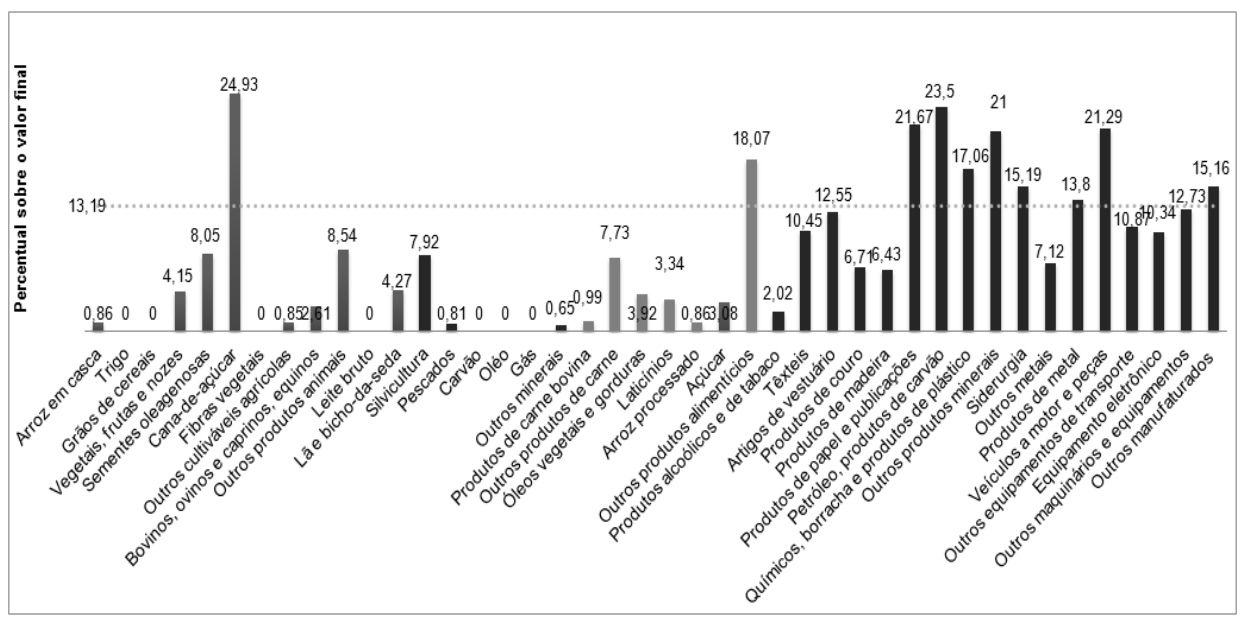

Figura 6 - Equivalente ad valorem das importações setoriais (2012)

Fonte: elaboração própria. 


\section{Aspectos da Modelagem}

\subsection{Modelo de Equilíbrio Geral Computável Utilizado ${ }^{10}$}

O modelo utilizado neste estudo foi o GTAP (Global Trade Analysis Project). Trata-se de um modelo de equilíbrio geral computável global, que considerada estruturas de mercado em competição perfeita. Em sua versão mais recente, o modelo representa 57 setores produtivos em 129 regiões do mundo. Seu conjunto de equações é totalmente baseado em fundamentos microeconômicos, contendo uma descrição detalhada do comportamento das famílias e firmas pertencentes a cada uma das regiões modeladas, além dos fluxos de comércio inter-regionais.

O GTAP qualifica-se como um modelo do tipo Johansen, no qual as soluções são obtidas resolvendo-se um sistema de equações linearizadas do modelo. A apresentação sistemática das soluções de Johansen para tais modelos é padrão na literatura (ver Dixon et al. 1992 e Dixon e Parmenter 1996).

Os três principais módulos do modelo GTAP são detalhados nos itens que seguem. ${ }^{11}$

\section{- Consumo das Famílias}

O modelo GTAP assume um consumidor representativo em cada região, o qual maximiza sua utilidade de maneira a alocar a renda regional entre consumo privado, serviços governamentais e poupança, em proporções fixas. A demanda privada do consumidor representativo é do tipo CDE (Constant Difference of Elasticities). Seguindo a tradicional hipótese de Armington (1969), bens domésticos e estrangeiros podem ser diferenciados por origem.

10 Ver Brockmeier (1996) ou Hertel (1997) para uma exposição detalhada do modelo GTAP.

11 A descrição dos módulos segue Zhang e Fung (2006), mas com uma maior riqueza de detalhes. 


\section{- Oferta das Firmas}

As firmas são price takers e maximizam lucro em uma estrutura de mercado perfeitamente competitiva. O comportamento "tomador" de preços, típico de mercados de commodities, fará com que cada preço reflita o custo marginal de produção do bem associado. Os 57 setores representados no modelo operam com tecnologia de retornos constantes de escala, seguindo uma mesma lógica de estrutura aninhada de produção. De maneira geral, no último estágio de produção uma dada commodity será produzida a partir da combinação de 57 compostos de inputs intermediários e um único composto de fatores primários de produção (trabalho, capital, terra e recursos naturais), segundo uma tecnologia Leontief (proporções constantes). O composto de fatores primários é formado a partir de uma tecnologia CES (Constant Elasticity of Substitution), combinando cada um dos fatores de produção mencionados, supondo-os substitutos imperfeitos. Cada um dos 57 compostos de inputs intermediários será também formado a partir de uma CES, subdividida em dois estágios. No primeiro estágio, o produtor doméstico poderá escolher entre os diversos fornecedores estrangeiros, os quais oferecem inputs substitutos imperfeitos, diferenciados a partir de sua origem. No segundo estágio, a escolha é feita entre o input similar doméstico e o composto de inputs similares importados, também por meio de uma CES. Portanto, não só a diferenciação entre produtos importados e domésticos, como também a diferenciação entre importados por origem, segue a hipótese de Armington (1969).

\section{- Fechamento}

Todos os fatores de produção (trabalho, capital, terra e recursos naturais) são considerados em pleno emprego e com mobilidade zero entre as regiões. Seguindo o fechamento clássico do modelo GTAP, capital e trabalho possuem livre mobilidade entre setores, mas o estoque de ambos é fixo por região. Já os fatores terra e recursos naturais possuem mobilidade intersetorial parcial, sendo que seus estoques também são considerados fixos por região, assim como a tecnologia das firmas. Todos os fatores de produção são homogêneos. No equilíbrio final, as taxas de retorno do investimento são equalizadas entre as regiões do modelo. 


\subsection{Modelagem dos Choques de Eficiencia Portuária}

A fundamentação teórica do modelo econométrico proposto por Hummels and Schaur (2013) parte de uma função demanda, derivada a partir da maximização de utilidade de um consumidor representativo sobre diferentes variedades de um bem $k$, produzido pelo exportador $j$, de acordo com uma função CES (Constant Elasticity of Substitution):

$$
U=\left(\sum_{j} \sum_{k} \lambda_{j}^{k}\left(q_{j}^{k}\right)^{\theta}\right)^{1 / \theta}
$$

onde $\theta=(\sigma-1) / \sigma$, e $\sigma$ é a elasticidade de substituição entre as distintas variedades do bem $k$, com origem nos diversos exportadores $j$.

Um parâmetro chave no modelo de Hummels e Schaur é $\lambda_{j}^{k}$, que captura uma dimensão de qualidade atribuída ao bem $k$, exportado pelo país $j$. A ideia central dos autores é associar os atrasos à qualidade do bem em questão, de modo que $\lambda_{j}^{k}$ é definido como:

$$
\lambda_{j}^{k}=e^{-\tau^{\kappa} \text { dias }_{j}}
$$

Desta forma, o aumento de um dia no tempo de translado de um dado bem $\mathrm{k}$ reduz a sua percepção de qualidade em $\lambda_{j}^{k}=e^{-\tau^{\kappa}}$. A resolução do problema do consumidor resulta na seguinte função demanda:

$$
q_{j}^{k}=\left(\frac{p_{j}^{k}}{\lambda_{j}^{k}}\right)^{-\sigma} E^{k}=\left(\frac{p_{j}^{k}}{e^{-\tau^{k} \text { days }_{j}}}\right)^{-\sigma} E^{k}
$$

onde $E^{k}$ corresponde às despesas reais do importador com o bem $k, p_{j}^{k}$ é o preço do bem $k$, exportado por $j$ e pago pelo consumidor (importador) representativo, incluindo os custos de produção, transporte, e o lucro da firma. Hummels \& Schaur (2013) estimam o equivalente ad valorem dos atrasos portuários - representado pelo parâmetro $\tau^{\kappa}$ - a partir da função demanda por importação representada em (3). Depreende-se, pois, que variações nos atrasos portuários para a entrega de um determinado bem $k$ impliquem variações nas preferências (utilidade) do importador pelo mesmo bem. Desta forma, fica clara a correspondência entre choques de eficiência portuária - os quais alteram o tempo de atraso para a entrega de um bem - e choques de demanda pelo produto importado $k$, com origem em $j$. Ademais, a especificação da demanda por bens importados 
(Equação (3)) segue a hipótese de Armington (1969), sendo consistente com a função de demanda por bens importados para o consumidor regional representativo, proposta no modelo GTAP.

A abordagem adotada neste trabalho seguirá, pois, a metodologia desenvolvida em Hertel et al (2001) para choques de eficiência portuária com o modelo GTAP, a qual também pode ser compreendida como um choque de demanda por importação e, desta forma, é capaz de representar variações na percepção de qualidade de um bem importado a partir de alterações no prazo de entrega, como proposto por Hummels e Schaur (2013). Hertel et al. (2001) baseiam-se em custos de transporte iceberg e introduzem o conceito de "preço efetivo" de uma commodity $i$, importada de um país $r$ aos preços domésticos no mercado de destino $s, P M S_{\text {irs }}^{*}$. Por sua vez, este preço efetivo se relaciona com o preço observado, $P M S_{\text {irs }}$ de acordo com $P M S^{*}=P M S / A M S$. A variável de ajuste $A M S$ é não observável e, no equilíbrio inicial, vale 1 , situação na qual o valor implícito do custo dos atrasos portuários é integralmente repassado aos agentes da economia.

Para uma variação positiva de $A M S$, correspondente ao equivalente $a d$ valorem estimado para o custo do atraso portuário de importação, haverá uma queda do preço efetivo da mercadoria importada $\left(P M S_{\text {irs }}^{*}\right.$.), consequência da redução integral dos atrasos portuários. Variações parciais de AMS corresponderão a reduções parciais, de igual proporção, dos custos dos atrasos portuários nas importações da commodity $i$, proveniente do país $r$, destinadas ao país $s$.

Quando esta teoria é incorporada ao modelo GTAP, e os preços de importação e as equações de demanda são totalmente diferenciados e reescritos como variações porcentuais, obtém-se as seguintes equações:

$$
q x s_{i r s}=-a m s_{i r s}+q i m_{i s}-\sigma_{m}^{i} \cdot\left[p m s_{i r s}-a m s_{i r s}-p i m_{i r s}\right]
$$

O preço composite das importações é definido por:

$$
\operatorname{pim}_{i s}=\sum_{k} \sigma_{i k s} \cdot\left[p m s_{i k s}-a m s_{i k s}\right]
$$

onde:

$\sigma_{m}^{i}=$ elasticidade de substituição entre os bens i importados;

qxs $s_{\text {irs }}=$ variação porcentual das exportações bilaterais do bem i, provenientes de $r$, destinadas a s; 
$\operatorname{qim}_{i s}=$ variação porcentual das importações totais do bem i, por s;

$p m s_{i r s}=$ variação porcentual no preço das importações do bem i, provenientes de $r$, com destino a s;

$\operatorname{pim}_{i s}=$ variação porcentual no preço médio das importações do bem i, por s;

$a m s_{i r s}=$ variação porcentual no preço efetivo do bem i importado por $s$, proveniente de $r$, devido a custos de transação não observáveis.

Das Equações (4) e (5) é possível compreender de que forma choques na variável são repassados aos agentes da economia. A Equação (4) revela que um aumento de , correspondente ao aumento da eficiência portuária na importação do bem $i$, pelo país $s$, diminui o preço efetivo do bem importado $i$, proveniente de $r$, tornando este país relativamente mais competitivo em relação ao resto do mundo, de acordo com a elasticidade de substituição . Ao mesmo tempo, e de forma compensatória, dado que a quantidade efetiva aumenta, menos importações são requeridas para suprir a demanda do país $s$. Já a Equação (5) revela que, com a redução dos atrasos na importação do bem $i$, proveniente de $r$, o preço médio das importações totais de $i$, com destino em $s$, tende a cair, aumentando a quantidade importada do bem $i$, em detrimento da produção local. ${ }^{12}$

\subsection{Análise de Sensibilidade}

Com o intuito de testar a robustez dos resultados obtidos, procedeu-se a uma análise de sensibilidade sistemática (SSA na sigla em inglês) dos resultados obtidos nas simulações. O objetivo é avaliar quão sensíveis são as soluções do modelo a variações nos valores de alguns parâmetros adotados, considerados de fundamental importância para os resultados obtidos. Como de praxe na modelagem EGC, possíveis erros de estimativas nas elasticidades de substituição entre bens domésticos e importados serão aqui avaliados. 12 Para uma ampla discussão sobre formas alternativas de modelagem de choques de eficiência portuá-
ria ver Fugazza e Maur (2008), cujas conclusões corroboram a estratégia adotada neste estudo. 
Os resultados da SSA correspondem a estimativas do valor médio e do desvio padrão de cada variável endógena do modelo, obtidos por meio da resolução do mesmo repetidas vezes para diferentes valores de parâmetros, selecionados através da quadratura de Strouds ${ }^{13}$ com distribuição triangular simétrica. ${ }^{14}$ Estas estimativas permitem a inferência do intervalo mais provável de valores para cada uma das variáveis. O intervalo de confiança, por sua vez, é elaborado de forma conservadora utilizando-se a desigualdade de Chebyshev, ${ }^{15}$ dado o desconhecimento quanto à distribuição de probabilidade das variáveis endógenas do modelo.

\section{Resultados}

\subsection{O Impacto da Facilitação do Comércio}

Foram estudados três cenários distintos para a estimativa do impacto econômico da facilitação do comércio sobre a economia do Brasil. No primeiro cenário, avaliou-se o impacto do aumento da eficiência portuária de forma unilateral. No segundo cenário, foram considerados ganhos de eficiência portuária não apenas no Brasil, como também em seus principais parceiros comerciais. ${ }^{16}$ Já no terceiro cenário, considerou-se um aumento de eficiência portuária em escala global.

Para a análise em questão, e em todos os cenários avaliados, foram desprezados os tempos médios de atrasos com a obtenção de documentos, tanto para exportação, quanto para importação. Este procedimento segue observação feita em Minor \& Tsigas (2008) e se justifica pelo fato da existência, segundo os autores, de vários documentos de natureza periódica e, portanto, não necessários marginalmente, ou seja, para cada ordem de

${ }^{13}$ A quadratura de Strouds é um caso particular da quadratura gaussiana, utilizada para tornar discretas as distribuições contínuas de variáveis. Os primeiros momentos idênticos entre a curva contínua e a discreta, que definem a ordem da quadratura, nesse caso são 3.

${ }^{14}$ Distribuição simétrica de probabilidade que varia linearmente de um valor máximo (max) até a média (med), com inclinação $-1 /(\max -m e d)^{2}$ e da média até um valor mínimo (min) com inclinação $1 /(\text { med }- \text { min })^{2}$.

${ }^{15}$ A desigualdade de Chebyshev afirma que, independentemente da distribuição da variável Y em questão, para cada número positivo $k$, a probabilidade de que o valor de $Y$ não esteja dentro de $k$ desvios padrões $(D)$ da média $(M)$ é inferior a $1 / k^{2}$. Assim, com $95 \%$ de certeza $\left(1-1 / 4,47^{2}\right)$, a média está dentro do intervalo entre $\left(M-4,47^{*} D\right)$ e $\left(M+4,47^{*} D\right)$.

16 Principais países considerados: EUA, China, Argentina, Alemanha, França, Itália e Holanda. 
exportação/importação realizada. Uma vez que neste estudo, os choques de eficiência portuária têm natureza marginal, a introdução do tempo de documentação poderia levar a distorções nos resultados obtidos.

Por fim, foi considerado que, de forma realista, os ganhos de eficiência portuária levariam a uma redução de cerca de $50 \%$ dos atrasos médios nas aduanas. Esta, portanto, seria uma conjectura sobre o máximo de redução esperado para o tempo médio de atrasos, após a implementação do Acordo de Facilitação do Comércio de Bali, no contexto da atual rodada Doha de negociações multilaterais de comércio da OMC. ${ }^{17}$

\subsubsection{Resultados}

Sob o ponto de vista da economia do Brasil, na medida em que mais países resolvem implementar as reformas de facilitação do comércio previstas no acordo de Bali, dois efeitos se contrapõem. Se por um lado haverá mais competição por parte de países exportadores que concorrem com as exportações Brasileiras, por outro lado o aumento da eficiência aduaneira nos países importadores tende a operar como um choque de demanda positivo para as exportações do Brasil. Como pode ser visto na Tabela 2, pelo impacto nos termos de troca do país, o resultado líquido destes dois efeitos tende a ser positivo para o Brasil, muito embora a maior contribuição dos termos de troca para o aumento da renda do país ocorra no cenário 1, quando o Brasil é o único país a auferir ganhos de eficiência portuária.

Sob o ponto de vista do estímulo ao crescimento do PIB, os ganhos para o Brasil tendem a ser maiores, quanto maior o número de países que implementam reformas de facilitação do comércio. Dado o impacto observado para o custo relativo dos fatores, o teorema de Stolper Samuelson ${ }^{18}$ sugere que os ganhos de termos de troca refletem o aumento dos preços de bens manufaturados exportados (capital intensivos), demandantes de mão de obra qualificada, em detrimento dos bens exportados intensivos em terra

17 O programa Portal Único de Comércio Exterior, ora implementado pelo MDIC e Receita Federal do Brasil, almeja a redução em cerca de $40 \%$ no tempo médio dos atrasos nas aduanas do Brasil, até o ano de 2017. Este programa, embora correlato, é uma iniciativa unilateral do governo brasileiro, independente das diretrizes firmadas no Acordo de Bali da OMC, em dezembro de 2013.

${ }^{18}$ A relação entre o custo relativo dos fatores e os termos de troca foi originalmente explicada no artigo clássico escrito por Wolfgang Stolper e Paul Samuelson "Protection and Real Wages", Review of Economic Studies, 9, Novembro, 1941, pp.58-73. 
(em geral, bens agrícolas). Mais ainda, sugere um aumento das taxas de crescimento da economia induzidas por exportações de bens manufaturados, para todos os cenários avaliados.

A Tabela 3 reporta os resultados das simulações para as exportações/importações setoriais do Brasil. Para todos os cenários avaliados, a redução dos atrasos aduaneiros causa impacto positivo nas importações do país, principalmente para os produtos relativamente capital intensivos. Quanto às exportações, há clara tendência para um aumento da participação dos produtos manufaturados na pauta exportadora do país, quanto maior o número de países que aderem às reformas de facilitação do comércio. Este resultado tem forte impacto de política pública, na medida em que a contínua primarização da pauta exportadora do país tem sido alvo de preocupação e debate entre policy makers do governo brasileiro. Em resumo, a redução dos atrasos portuários, para todos os cenários avaliados, altera os preços relativos de forma favorável aos bens manufaturados produzidos no Brasil. ${ }^{19}$

A Tabela 4 ilustra os resultados obtidos para as demais regiões do mundo, no que tange ao impacto da facilitação do comércio sobre o PIB e os termos de troca. Como esperado, quando as medidas de facilitação do comércio são implementadas apenas no Brasil (Cenáriol), o impacto no resto do mundo tende a ser próximo de zero. Para os demais cenários (cenários 2 e 3), na medida em que as reformas são progressivamente implantadas no resto do mundo, os impactos sobre o PIB e os termos de troca passam a ser relevantes.

Os números reportados sugerem que as reformas tendem a estimular o crescimento do PIB em todas as macro regiões representadas. Para os termos de troca, contudo, os resultados são menos uniformes. Em particular para o cenário 3, a América do norte e a EU_28 são as únicas regiões do mundo onde o impacto nos termos de troca contribuem negativamente para a criação de renda e bem-estar. Entre outros fatores, o maior estímulo causado às exportações de produtos manufaturados nos países em desenvolvimento, que estão relativamente mais distantes da fronteira de

${ }^{19}$ Dado que os maiores custos dos atrasos estão concentrados em bens de maior valor agregado, e os choques aplicados foram uniformes entre os setores (50\%), este resultado era, ao menos qualitativamente, esperado. Choques heterogêneos (por países e setores) certamente aproximariam melhor a realidade dos efeitos esperados para o Acordo de Bali. Contudo, dado o viés existente na distribuição dos custos dos atrasos - com maior penalização para bens de alto valor agregado - as implicações qualitativas deste trabalho parecem ser robustas a possíveis estratégias alternativas para os choques. 
eficiência, exerce impacto negativo sobre o preço das exportações dos países desenvolvidos.

Tabela 2 - Resultado Macroeconômico

\begin{tabular}{lrrr}
\hline & Cenário 1 (\%) & Cenário 2 (\%) & Cenário 3 (\%) \\
\hline PIB & 0,52 & 0,64 & 1,14 \\
Termos de troca & 1,69 & 0,86 & 1,40 \\
Trab. n/qualificado & 0,77 & 0,77 & 1,25 \\
Trab. qualificado & 0,97 & 0,98 & 1,69 \\
Retorno do Capital & 0,71 & 0,73 & 1,21 \\
Retorno da Terra & $-4,52$ & $-2,11$ & $-4,79$ \\
\hline
\end{tabular}

Fonte: Elaboração Própria. Modelo GTAP.
Tabela 3 - Resultado Macroeconômico

\begin{tabular}{lrrrrrr}
\hline Setor & \multicolumn{2}{c}{ Cenário 1 (\%) } & \multicolumn{2}{c}{ Cenário 2 (\%) } & \multicolumn{2}{c}{ Cenário 3 (\%) } \\
\hline & Exp & Imp & Exp & Imp & Exp & Imp \\
\cline { 2 - 7 } Agricultura & $-2,30$ & 4,00 & 0,60 & 1,51 & $-5,00$ & 2,56 \\
Ind. Extrativa & $-3,26$ & 1,56 & $-3,97$ & 0,66 & 3,58 & 7,81 \\
Agronegócio & $-8,16$ & 12,29 & $-7,52$ & 11,53 & $-5,65$ & 12,42 \\
& 11,6 & 12,05 & 12,67 & 11,95 & 17,56 & 20,13 \\
Manufaturas & 1 & & & & & \\
Serviços & $-9,13$ & 5,39 & $-5,69$ & 3,62 & $-7,87$ & 5,09 \\
\hline
\end{tabular}

Fonte: Elaboração Própria. Modelo GTAP.

Tabela 4 - Desempenho da Economia Internacional

\begin{tabular}{lcccccc}
\hline Região & \multicolumn{2}{c}{ Cenário 1 } & \multicolumn{2}{c}{ Cenário 2 } & \multicolumn{2}{c}{ Cenário 3 } \\
\hline & PIB & $\mathrm{P}_{\text {exp }} / P_{\text {imp }}$ & PIB & $P_{\text {exp }} / P_{\text {imp }}$ & PIB & $P_{\text {exp }} / P_{\text {imp }}$ \\
Oceania & 0,00 & 0,00 & 0,16 & $-0,69$ & 1,10 & 1,22 \\
Leste Asiático & 0,00 & $-0,03$ & 0,16 & $-0,17$ & 0,98 & 0,33 \\
Sudeste Asiático & 0,00 & $-0,01$ & 0,28 & $-0,47$ & 2,16 & 0,65 \\
Sul Asiático & 0,01 & 0,03 & 0,10 & $-0,43$ & 2,12 & 2,07 \\
América do Norte & 0,01 & $-0,03$ & 0,41 & $-0,46$ & 0,54 & $-0,70$ \\
América Latina & 0,10 & $-0,09$ & 0,34 & $-0,73$ & 1,61 & 1,23 \\
EU_28 & 0,00 & $-0,02$ & 0,37 & $-0,51$ & 0,71 & $-0,49$ \\
Resto do Mundo & 0,01 & $-0,01$ & 0,35 & $-0,71$ & 1,87 & 0,58 \\
\hline
\end{tabular}

Fonte: Elaboração própria. Modelo GTAP. Para o cenário 2, o desempenho das regiões não inclui os principais parceiros comerciais do Brasil. Para estes, considerando-se o PIB e os termos de troca, respectivamente, os resultados são: China $(1,57 ; 0,70)$, EUA $(0,28 ; 0,31)$, Argentina $(1,28 ; 1,65)$, França $(1,01$; $1,03)$, Itália $(1,24 ; 1,78)$, Holanda $(0,71 ; 0,69)$, Alemanha $(0,82 ; 0,97)$.

\subsection{Análise de Sensibilidade}

Para verificar a robustez dos resultados obtidos, analisou-se o impacto de variações nos parâmetros de elasticidade do modelo GTAP, sobre as variáveis endógenas PIB e termos de troca do Brasil. Para tanto, assumiuse que os parâmetros de elasticidade do modelo (elasticidade de substituição entre produtos domésticos e importados para os diversos setores 
analisados) ${ }^{20}$ são variáveis aleatórias com distribuição triangular simétrica no intervalo de $+/-25 \%$ do valor original da elasticidade empregada. ${ }^{21} \mathrm{~A}$ análise sistemática retorna o primeiro e segundo momentos das variáveis endógenas de interesse, permitindo, de forma conservadora, a estimativa de um intervalo de confiança por meio da desigualdade de Chebyshev. Os resultados reportados na Tabelas 5 revelam que, com 95\% de probabilidade, os resultados estimados para o crescimento do PIB e termos de troca do Brasil estão compreendidos em intervalos de confiança relativamente próximos da média, a qual é idêntica aos valores simulados para cada cenário. Portanto, eventuais incertezas sobre os parâmetros de elasticidade do modelo não parecem ser capazes de modificar, ao menos qualitativamente, os resultados obtidos para o Brasil, a partir das simulações realizadas.

Tabela 5 - Análise de sensibilidade

\begin{tabular}{llllll}
\hline Cenário 1 & \multicolumn{3}{c}{ Cenário 2 } & \multicolumn{3}{c}{ Cenário 3 } \\
\hline $\begin{array}{l}\text { Produto Interno Bruto } \\
\text { Média }\end{array}$ & Inter. Conf. & Média & Inter. Conf. & Média & Inter. Conf. \\
0,52 & {$[0,43 ; 0,61]$} & 0,64 & {$[0,55 ; 0,73]$} & 1,14 & {$[0,96 ; 1,32]$} \\
\hline Termos de Troca & & & & & \\
\hline Média & Inter. Conf. & Média & Inter. Conf. & Média & Inter. Conf. \\
\hline 1,69 & {$[1,47 ; 1,91]$} & 0,86 & {$[0,73 ; 0,99]$} & 1,40 & {$[1,13 ; 1,67]$} \\
\hline
\end{tabular}

Fonte: Elaboração própria. Modelo GTAP.

\subsection{Implicações de Política Pública}

O crescimento das cadeias globais de valor vem dando novo impulso ao debate sobre políticas industriais no Brasil e no mundo. Antigos paradigmas, como o imperativo do adensamento das cadeias de produção domésticas ou mesmo a essencialidade da exportação de produtos de alto valor agregado para o crescimento de um país, vêm sendo cada vez mais colocados à prova, diante do dinamismo alcançado por economias emergentes da Ásia, como a China e Vietnã, ou mesmo do leste Europeu, como a República Tcheca

${ }^{20} \mathrm{Na}$ base de dados GTAP8, os valores estimados para as elasticidades de substituição setoriais são: Agricultura: 2,44; Indústria Extrativa: 5,12; Agronegócio: 2,84; Manufaturas: 3,33; Serviços: 1,94. Dado que o canal de transmissão primário dos choques de eficiência portuária se dá por meio das trocas comerciais entre os países/regiões, estes parâmetros são de fundamental importância para os resultados do modelo.

21 Uma outra possibilidade, obviamente menos realista, seria considerar uma distribuição uniforme. 
e a Hungria. Ao contrário, o modelo de industrialização seguido por estas economias pressupõe a fragmentação internacional da atividade produtiva e o consequente aumento do conteúdo de bens intermediários importados em suas exportações, resultando em um menor valor adicionado doméstico por unidade de produto exportada.

Para o caso do Brasil, tão ou mais importante que políticas industriais voltadas para setores específicos da economia, parece ser a implementação de políticas públicas de cunho horizontal. São exemplos de tais políticas aquelas focadas na redução generalizada dos altos custos de transação existentes no país, refletidos em uma infraestrutura logística que dá claros sinais de esgotamento, no seu persistente isolacionismo comercial, com a consequente permanência de altas barreiras tarifárias e regulatórias, além da má qualidade do ambiente de negócios doméstico e a insuficiência de mão de obra qualificada.

Sem negar a importância estratégica de políticas de cunho setorial, para setores onde há claras externalidades a serem incentivadas, é pouco provável que as mesmas alcancem a plenitude dos objetivos a que se propõem, sem a melhoria expressiva do quadro geral de negócios do país. Dito de outra forma, o impacto esperado das políticas setoriais tende a ser muito reduzido em um ambiente de baixa eficiência sistêmica no uso dos recursos produtivos de uma economia. A melhoria da eficiência sistêmica, pois, é matéria para as políticas públicas de cunho horizontal, quais sejam, aquelas capazes de impactar positivamente todos os setores da economia, incentivando o aumento da produtividade total dos fatores de produção.

Sob o ponto de vista das implicações de políticas públicas de cunho horizontal, os resultados deste trabalho oferecem ao menos duas contribuições. Em primeiro lugar, é oferecida uma perspectiva comparada da magnitude das barreiras aduaneiras (sob o ponto de vista dos atrasos de importação e exportação) para várias regiões do mundo, com destaque para o Brasil e seus principais parceiros comerciais. Para além das tradicionais tarifas de importação, os valores estimados proporcionam ao formulador de política uma visão mais detalhada sobre as barreiras aduaneiras mais relevantes, por origem e destino, impostas ao comércio exterior no Brasil. Em segundo lugar, com base nas barreiras aduaneiras estimadas para o país, é feita uma análise de impacto acerca dos possíveis benefícios para a economia brasileira, caso os atrasos domésticos sejam reduzidos em $50 \%$, sobretudo diante da expectativa de implementação futura do Acordo Mundial de 
Facilitação do Comércio. Os resultados reportados revelam alta sensibilidade do comércio exterior brasileiro às barreiras aduaneiras, principalmente para produtos de maior valor agregado, fato que sinaliza a importância da melhoria da eficiência aduaneira para a integração da indústria brasileira ao comércio mundial, sobretudo às cadeias globais de valor. Dada a natureza marcadamente regulatória dos atrasos portuários no Brasil, simbolizada por excesso de burocracia e ineficiência micro-gerencial de procedimentos, os resultados deste estudo sugerem que medidas de custos relativamente baixos e rápida implementação podem ter impactos significativos sobre a produtividade da economia brasileira, por meio do aumento da sua participação no comércio internacional e melhoria da eficiência na alocação dos fatores produtivos.

O tema da facilitação de comércio ganhou destaque no debate econômico internacional com a celebração do Acordo de Bali, em dezembro de 2013, no âmbito da OMC, e sua aprovação final pelos membros da organização em dezembro de 2014. De forma geral, o acordo de Bali propõe um cronograma ambicioso de medidas para os países membros da OMC, com foco na redução de duas categorias de custos de transação ao comércio internacional: os custos diretos e indiretos. Como já mencionado, os custos diretos ao comércio se caracterizam pelo consumo de recursos reais na movimentação de bens, sendo representados por encargos e taxas aduaneiras em geral, além de taxas de carga, descarga e armazenamento de mercadorias. Já os custos indiretos são aqueles relacionados ao custo econômico dos atrasos nas aduanas, devido à existência de procedimentos ineficientes. Como já mostrado nas seções anteriores, a redução dos custos indiretos é potencialmente mais significativa para o comércio mundial que a própria redução das tarifas de importação atualmente aplicadas.

A análise detalhada do texto final do Acordo de Bali permite concluir que a maior parte do seu conjunto de medidas se refere à redução dos custos indiretos (atrasos) nas aduanas dos países membros da OMC, seja pelo aumento da informatização dos procedimentos aduaneiros em geral, pela maior racionalização dos procedimentos de inspeção e requerimentos de segurança, além de medidas relacionadas a maior transparência e implantação de mecanismos de facilitação de acesso à informação relevante. Segundo a OMC (WTO 2015), o Acordo de Facilitação de Comércio, uma vez implementado, pode aumentar as exportações globais em cerca de um trilhão de dólares por ano. 
Aqui no Brasil, em consonância com o Acordo de Bali, o programa Portal Único de Comércio Exterior, ora em implantação, visa a reformulação de processos de importação, exportação e trânsito aduaneiro no Brasil, até o final do ano de 2017. De acordo com as informações disponibilizadas pelo governo, ${ }^{22}$ a implantação do programa resultará na redução do prazo médio de exportação de 13 para 8 dias (38\%), como também na redução do prazo médio de importação de 17 para 10 dias (40\%) nas aduanas brasileiras, percentuais próximos aos simulados neste artigo. Conforme reportado na seção 5 , dada a magnitude relativa das barreiras dos atrasos aduaneiros no Brasil, é possível inferir que a implantação do programa resulte não só em forte estímulo à corrente de comércio do país como um todo, mas que este efeito seja particularmente relevante para a indústria de transformação brasileira. Além da montagem e operacionalização do guichê único, previsto pelo Acordo de Bali, o programa brasileiro também abordará outros tópicos previstos no Acordo e que estão majoritariamente voltados para a redução dos atrasos, tais como: 1. Disponibilidade de informação (Artigos l e 2); 2. Formalidades e Documentos (Artigos 7 e 10); 3. Formalidades e Automação (Artigos 7 e 10); 4. Cooperação interna entre aduanas (Artigos 9 e 12); entre outros.

Por fim, outra iniciativa relevante ora sendo implementada no Brasil, ainda que de forma preliminar e em relativo atraso com relação ao resto do mundo, refere-se ao programa Operador Econômico Autorizado (OEA). Trata-se de um programa de certificação dos intervenientes da cadeia logística de um produto a ser comercializado, que representam baixo grau de risco em suas operações comerciais, tanto em termos de segurança física da carga, quanto ao cumprimento de suas obrigações aduaneiras. O programa, de adesão voluntária e objetiva até 2019, busca atingir a meta de 50\% das declarações de exportação e de importação registradas no país por empresas certificadas OEA. Segundo estimativas do governo, a implantação do programa OEA trará redução adicional de custos totais de exportação/ importação da ordem de $20 \%$ para as empresas certificadas.

Como sugerido pela análise ex-ante realizada neste artigo, tanto o programa Portal Único de Comércio Exterior, quanto o programa OEA, ao abordarem "gargalos" burocráticos relevantes nas aduanas Brasileiras, são ferramentas potencialmente valiosas para impulsionar o comércio exterior do país, caso sejam de fato implementadas em sua integralidade.

${ }^{22}$ Ver http://portal.siscomex.gov.br/conheca-o-portal/programa-portal-unico-de-comercio-exterior. 


\section{Comentários Finais}

Este artigo ressalta a importância do tempo como fator relevante para o aumento da competitividade da indústria brasileira. Ao penalizar em maior grau o comércio internacional de bens manufaturados, a deterioração da logística portuária no Brasil parece contribuir, ao menos em parte, para o fenômeno da primarização da pauta de exportação do país. De forma mais geral, constitui barreira significativa a uma maior inserção internacional da indústria de transformação brasileira na economia global, limitando, portanto, seu potencial de ganhos de produtividade.

O forte crescimento do comércio global por via aérea, observado nas últimas quatro décadas (cerca de 2,5 vezes mais rápido que o comércio por via marítima), concomitantemente ao crescimento do comércio internacional de bens intermediários, que hoje representam cerca de $66 \%$ das exportações mundiais, ressaltam a importância do fator tempo para as relações de comércio atuais, as quais são fortemente baseadas na integração das capacidades produtivas das economias em escala global.

Com as cadeias globais de valor, o conceito de produtividade deixa de ser local e passa a ser global. É fundamental, pois, que a indústria brasileira, visando assegurar sua competitividade no longo prazo, busque aumentar a sua inserção internacional. No sentido mais amplo, os resultados deste artigo sugerem que políticas públicas de cunho horizontal, voltadas para a melhoria da logística de comércio exterior do Brasil, podem contribuir, de forma significativa, para este fim. Em particular, o tema da facilitação comercial, objeto do recente Acordo de Bali e de políticas ora em curso no Brasil, passa a ter caráter estratégico para a agenda de crescimento econômico nacional.

\section{Referências}

Anderson, J. 1979. “A Theoretical Foundation for the Gravity Equation”. American Economic Review 69(1): 106-116.

Anderson, J., Wincoop, E. V. 2003. "Gravity and Gravitas: A Solution to the Border Puzzle”. American Economic Review 93(1): 170-192.

APEC. 1999. "Assessing APEC Trade Liberalization and Facilitation - 1999 update”. Technical report, APEC Economic Committee, Singapore. 
Armington, P.S. 1969. “A Theory of Demand for Products Distinguished by Place of Production”. Staff Papers, IMF 16(1): 159-178.

Brockmeier, M. 1996. "A Graphical Exposition of the GTAP model”. GTAP Technical/Paper/No.8.www.gtap. agecon.purdue.edu/resources/res_display.asp?RecordID $=31$.

Dee, P. 1998. "The Comprehensiveness of APEC's Free Trade Commitment". Session VIII in The Economic Implications of Liberalizing, Publication 3101, US International Trade Comission, Washington, D.C.

Dennis, A. and Shepherd, B. 2011. "Trade facilitation and export diversification". The World Economy, 34(1):101-122.

Dixon, P. B., Pearson, K. 1992. "Notes and Problems in Applied General Equilibrium Economics". North-Holland Amsterdam.

Dixon, P. B., Jorgenson, D. W. 2013. “Handbook of Computable General Equilibrium Modeling”. North-Holland, vol.B.

Djankov, S., Freund, C., Pham, C.S. 2010. "Trading on Time”. The Review of Economics and Statistics 92(1): 166-173.

Francois, J., Meijl, H. V., Tongeren, F.V. 2003. "Economic Benefits of the Doha Round for the Netherlands". Project Report, Agricultural Economics Research Institute, La Haye.

Fugazza, M., Maur, J.C. 2008. "Non-tariff barriers in CGE models: How useful for policy?”. Journal of Policy Modeling 30(3): 475-490.

Ginsburgh, V., Keyzer, M. 1997. "The Structure of Applied General Equilibrium Models”. The MIT Press.

Hertel, T. W. 1997. "Global trade analysis: modeling and applications". Cambridge university press.

Hertel, T. W., Walmsley, T. L., Itakura, K. 2001. "Dynamic Effects of the "New-Age" Free Trade Agreement Between Japan and Singapore”. Journal of Economic Integration 16(4): 446-8.

Hummels, D., Schaur, G. 2013. "Time as a Trade Barrier”. American Economic Review 103(7).

Iwanow, T., Kirkpatrick, C. 2007. “Trade Facilitation, Regulatory Quality and Export Performance”. Journal of International Development 19(6): August, 735-753.

Minor, P., Tsigas, M. 2008. "Impacts of Better Trade Facilitation in Developing Countries". $11^{\text {th }}$ Annual GTAP Conference, Helsinki, Finland, 12-14, June.

Nordas, H., Piermartini, R. 2004. "Infrastructure and Trade". WTO Economic Research and Statistics Division. Staff Working Paper ERSD-2004-04, WTO, Geneva.

OECD. 2003. "Quantitative Assessment of the Benefits of Trade Facilitation". Working Party of the Trade Committee, TD/TC/WP31.

Persson, M. 2008. "Trade Facilitation and the EU-ACP Economic Partnership Agreements". Journal of Economic Integration 23(3):518-546.

Zhang, J., Fung, H. 2006. “Winners and Losers: Assessing the Impact of Chinese Yuan Appreciation”. Journal of Policy Modeling, Elsevier 28(9): 995-1009.

Yotov, Y.V., Piermartini, J., Monteiro, J.A., Larch, M. 2016. "An Advanced Guide to Trade Policy Analysis: The Structural Gravity Model". Co-published by Unctad and WTO.

Wilson, J.S., Mann, C.L., Otsuki, T. 2005. “Assessing the Benefits of Trade Facilitation: A Global Perspective”. The World Economy 28(6): June, 841-871.

World Trade Organization. 2015. "Speeding up Trade: Benefits and Challenges of Implementing the WTO Trade Facilitation Agreement”. World Trade Report, 2015. 